\title{
Estilos de aprendizagem e a sala de aula dialógica
}

\author{
Learning styles and the dialogic classroom
}

Estilos de aprendizaje y el aula dialógica

LUCILO ANTÔNIO RODRIGUESIDa

\section{Resumo}

Os estilos de aprendizagem, apesar de consolidados, enfrentam ainda alguns desafios, dentre os quais, a aprendizagem individual em sala de aula. Argumenta-se que, em um espaço tradicional, o docente encontraria dificuldades intransponíveis ao ter que trabalhar com os estilos de cada aluno. A solução nesse caso seria a recorrência aos espaços virtuais que, além de ser mais adequados aos estilos de aprendizagem, também seriam uma resposta aos imensos desafios impostos pela sociedade tecnológica. Essa saída não considera que determinados atributos da sala de aula começam a se fazer presente no exato momento histórico em que os cursos de EAD ultrapassam os presenciais. Sem prejuízo para a educação a distância, este artigo tem por objetivo fazer uma defesa do uso dos estilos de aprendizagem na sala de aula. Considera-se que a abertura para o diálogo realiza a verdadeira vocação da sala de aula ao negociar com o aluno cada estilo pessoal, ao contrário do que parece ocorrer nos ambientes virtuais, nos quais uma agência tecnológica, travestida em tabelas, números e gráficos, determina os estilos individuais. A pesquisa bibliográfica norteouse sobretudo em artigos publicados em língua portuguesa e espanhola. Além da pesquisa, propôs-se também um exemplo de estratégia com o uso de estilos de aprendizagem. Os resultados evidenciaram uma maior flexibilidade dos estilos de aprendizagem, sugerindo que o adensamento do conhecimento pode ser realizado de maneira horizontal e, portanto, mais democrática.

Palavras-chave: Estilos individuais. Estilos pessoais. Cultura cognitiva digital.

\section{Abstract}

Although consolidated, learning styles still face challenges, such as individual learning in the classroom. It is argued that, in a traditional space, teachers would be facing insurmountable difficulties as they have to work with different styles of each student.

\footnotetext{
a Universidade Estadual de Mato Grosso do Sul (UEMS), Paranaíba, MS, Brasil. Doutor em Letras, e-mail: Iuciloterra@terra.com.br
} 
The solution in this case would be to turn to virtual spaces that are not only more suitable to different learning styles, but that would also be a response to major challenges imposed by the technological society. This option does not take into account that certain features of the classroom start to emerge at the exact same time when distance learning overcomes face-to-face instruction. Without prejudice to distance education, this article aims to advocate the use of learning styles in the classroom. Openness to dialogue is considered to fulfill the true vocation of the classroom by negotiating each personal style with students, contrary to what seems to be the case in virtual environments, where a technological agency, in the form in tables, numbers and graphs, determines individual styles. The bibliographic research was mainly based on articles published in Portuguese and Spanish. In addition to research, an example of strategy using learning styles was also proposed. Results showed a greater flexibility of learning styles, suggesting that knowledge can be increased horizontally and, therefore, more democratically.

Keywords: Individual styles. Personal styles. Digital cognitive culture.

\section{Resumen}

Los estilos de aprendizaje, aunque consolidados, todavía afrontan algunos retos, entre ellos el aprendizaje individual en aula. Se argumenta que, en un espacio tradicional, el docente encontraría dificultades infranqueables cuando tiene que trabajar con los estilos de cada alumno. La solución en este caso estaría en recurrir a los espacios virtuales que, además de ser más adecuados a los estilos de aprendizaje, serían también una respuesta a los inmensos retos que los impone la sociedad tecnológica. Esta opción no considera que determinados atributos del aula empiezan a hacerse presentes en el exacto momento histórico en que los cursos de EAD sobrepasan los presenciales. Sin pérdida para la educación a distancia, este artículo tiene por objetivo entablar una defensa del uso de los estilos de aprendizaje en aula. Se considera que el abrirse al diálogo realiza la verdadera vocación del aula cuando negocia con el alumno cada estilo personal, al revés de lo que parece suceder en los ambientes virtuales, en los cuales una agencia tecnológica, convertida en tablas números y gráficos, determina los estilos individuales. La investigación bibliográfica se orientó sobre todo en artículos publicados en lengua portuguesa y española. Además de la investigación, se planteó también un ejemplo de estrategia con el uso de estilos de aprendizaje. Los resultados evidencian una mayor flexibilidad de los estilos de aprendizaje al sugerirse que la densificación del conocimiento se puede realizar en modo horizontal y, luego, más democrático.

Palabras clave: Estilos individuales. Estilos personales. Cultura cognitiva digital.

\section{Introdução}

Os estudos sobre os estilos de aprendizagem (EA) conheceram nos últimos anos um rápido crescimento. Domingo J. Gallego e Catalina M. Alonso (2016) relatam, no prólogo da obra Estilos de Aprendizagem e inovação pedagógica que cerca de 
600 trabalhos foram apresentados no VII Congresso Mundial de Estilos de Aprendizagem, celebrado em Bragança, Portugal nos dias 4, 5 e 6 de julho de 2016. A quantidade de artigos disponibilizados no Google Scholar, somente em língua espanhola, ultrapassa a casa dos milhares, o que demonstra, a nosso ver, a consolidação dos EA no âmbito do ensino, da aprendizagem e da educação de um modo geral. Há, no entanto, um grupo de autores que se destacam, posto que já foram exaustivamente estudados. Refiro-me principalmente aos trabalhos de Felder \& Silverman (1988), Terrel \& Dringus (2000), Alonso e Gallego (2000), Olds, Spindle \& Cereola (2007).

Apesar de abundantes os EA estão permeados pelo discurso da eficiência. Assim, Barros et al. (2016), na aresta do pensamento de Alonso e Galego (2000), sustenta que eles seriam úteis para classificar e analisar comportamentos, ponderando, no entanto, que há o risco de se etiquetar indivíduos. Outros autores, como Gallego Rodriguez e Martinez Caro (2003, p. 9) afirmam ser muito difícil em uma sala de aula tradicional conciliar a docência aos estilos individuais dos alunos. Por outro lado, Barros em Estilos de aprendizagem e uso das tecnologias (2013), em uma perspectiva diferente, sinaliza que a cultura virtual ainda não foi sistematizada pela educação. Para ela, no entanto, essa subutilização não estaria ligada propriamente aos recursos tecnológicos, mas à criação de uma ambiência cultural. Outro aspecto que chama a atenção é o fato de que em muitos trabalhos a tecnologia é convocada para a tarefa urgente de auxiliar a escola nos novos tempos em que se exige cada vez mais rapidez e eficiência.

Julgamos que em muitos aspectos a sala de aula e os espaços virtuais são semelhantes. No entanto, à medida que crescem os cursos de Educação a distância (EAD), a percepção sobre as diferenças entre esses dois espaços ultrapassa as expectativas iniciais a ponto de não se tratar, apenas, de modalidades (presencial e a distância), mas de uma transformação mais complexa e que não envolve apenas questões de ensino e aprendizagem: elas se alargam e nos obrigam a lançar um olhar para o contexto histórico e social e, mais do que isso, elas se alargam e ameaçam redimensionar o próprio conceito do que seja o ser humano.

Sem prejuízo para as abordagens que defendem de maneira entusiástica o espaço virtual no processo de ensino e de aprendizagem, neste artigo defenderemos 
a permanência da sala de aula, uma vez que ela guarda aspectos específicos não reprodutíveis nos ambientes virtuais como, por exemplo, o diálogo face a face.

\section{Apontamentos sobre a tecnologia}

Concordamos com Barros (2013) quando afirma que a cultura virtual e/ou digital não teria sido ainda sistematizada pela educação. Há motivos para que isso não tenha ocorrido; dentre estes, a própria cultura da sala de aula que tende a resistir a toda forma de discurso dominante. Não se está se falando da resistência dos professores que se recusam a utilizar os recursos tecnológicos, mas do modo de ser da sala de aula que, felizmente é dialógico e dialético. Nesse sentido, entende-se que cultura tecnológica precisa aprender a dialogar com a escola. Faz-se necessário compreender que a escola, pela sua própria natureza, opera em uma outra velocidade: ela não poderia de forma alguma acelerar-se no mesmo ritmo das redes sociais.

\section{A tecnologia demanda um novo homem?}

Uma das críticas recorrentes à sala de aula vem de autores que consideram ser o espaço virtual o local mais adequado para a adaptação do ensino e da aprendizagem em um contexto social cada vez mais fugaz, veloz e complexo.

No prólogo da obra Estilos de aprendizagem e inovação pedagógica (BARROS et al., 2016), Gallego e Alonso reaviavam a famosa lei de Revans: "Un organismo sigue vivo, si y sólo si es capaz de cambiar a un ritmo al menos tan veloz como el entorno" 1 (2016, não p.). A referência a essa lei aparece recorrentemente em produções acadêmicas de língua espanhola. Vejamos alguns exemplos.

Isabel Martínez Peral (2010) ao citar a lei de Revans, propõe que a experiência educativa em sala de aula deve estar comprometida com uma iniciativa inovadora e que atenda a diversidade que existe nas escolas e que se adapte aos novos tempos, atualizando conteúdos e propondo metodologias e enfoques nos processos de aprendizagem da leitura e da escrita.

\footnotetext{
1 "Um organismo permanece vivo se e somente se for capaz de mudar a um ritmo pelo menos tão veloz quanto o seu entorno" (tradução nossa).
} 
Para José Antonio Marina (2016), aprender é o recurso da inteligência para sobreviver e progredir em um ambiente de contínuas mudanças. Ele acrescenta que, quando essas mudanças eram lentas, uma breve etapa de formação era suficiente para toda a vida, porém, salienta o autor, como vivemos um tempo de mudanças aceleradas, é mister que a aprendizagem deve também ser contínua e veloz.

Joan Pifarré Vidal (2008) argumenta que, se seguirmos a terminologia da lei de Revans, estaremos inovando porque, no que diz respeito ao terreno da competência leitora, a proposta é revolucionar o ritmo de nosso entorno.

Segundo Mariano Fernández Enguita (2007) a inovação é de fato condição de sobrevivência e, por conseguinte, é a condição de sucesso do organismo em um ambiente em rápida transformação. Em razão disso, ela poderia ser formulada nos termos da lei de Revans.

De acordo com López Rupérez, García García e Expósito Casas (2017), conquanto seja uma regra vinculada a uma reflexão baseada na experiência e não propriamente em uma lei, entendida no sentido científico do termo, a lei de Revans enfatiza a importância da aprendizagem, das organizações ou dos sistemas organizados quando imersos em um contexto dinâmico que exige a capacidade de adaptação como condição de sobrevivência.

Todas essas formulações se baseiam na constatação de que vivemos em um mundo imerso na tecnologia e que se faz necessário se adaptar com urgência a esse local em constante transformação.

Outra crítica recorrente sustenta-se na hipótese de que os EA não poderiam ser realizados com eficiência na sala de aula. Digno de nota é um comentário introdutório sob o tópico "Estilos de aprendizagem em aula" da obra Estilos de aprendizaje: desafios para una educación inclusiva e innovadora, o qual sustenta que, de um ponto de vista prático, seria impossível ajustar-se os diferentes estilos de aprendizagem de todos os estudantes, tendo em vista que o tempo dedicado a cada um seria demasiado breve (RODRÍGUEZ et al. 2015). Apesar do comentário introdutório, o texto sobre os estilos de aprendizagem em sala de aula não se vale desse argumento.

Insistimos que os espaços da tecnologia não são neutros e a desconsideração de sua própria lógica pode interditar o desenvolvimento não apenas da educação, 
mas, inclusive, da inovação. A seguir faremos alguns apontamentos sobre a tecnologia digital com o objetivo de fortalecer o nosso argumento sobre a defesa da sala de aula.

\section{Técnica e tecnologia}

Para Lúcia Santaella (2012, p. 71), técnica é um sistema de "habilidades que são introjetadas pelo indivíduo" e tecnologia é a incorporação dessas mesmas técnicas mediante um dispositivo situado fora do corpo humano. Em um laborioso trabalho intitulado "Técnica, tecnologia e tecnociência: da filosofia antiga à filosofia contemporânea", Leonardo Marques Kussler busca esclarecer a pertinente relação entre técnica e tecnologia.

Para Kussler, a técnica está encerrada na tecnologia contemporânea. Para discorrer sobre técnica e tecnologia o autor se propõe a elaborar uma análise etimológica. Após percorrer conceito de téchnē proposto por Platão e Aristóteles ele chega à conclusão de que essa palavra não corresponde ao significado moderno de técnica. A téchnè se realiza enquanto um saber fazer/arte e um saber fazer/conhecimento no âmbito antropocêntrico, enquanto a técnica moderna tende a condicionar o ser humano. Nesse sentido, a ênfase "[...] não mais se dá sobre o homem, senão que na técnica que o condiciona, adquire autonomia e, de certa forma, como tecnologia, se mescla ao que seja ser humano" (KUSSLER, 2015, p. 192).

O problema central para Kussler se resume na constatação segundo a qual no passado o homem ocupava um papel ativo frente à técnica, enquanto na contemporaneidade a vida humana parece se restringir à técnica e à tecnologia (2015, p. 193).

Uma parte considerável dos trabalhos acadêmicos enfatizam os aspectos técnicos e não problematizam o lugar do homem frente às inovações tecnológicas. No caso específico da relação entre ensino, estilos de aprendizagem e ambientes virtuais observa-se que o interesse, em muitos casos, é oportunizar uma aprendizagem individualizada. Assim, espera-se que com o auxílio de tabelas, gráficos e softwares os produtos educacionais possam ser entregues de acordo com o 
perfil do cliente, exatamente como ocorre hoje nas redes sociais com relação aos produtos que são ofertados a partir do rastreamento de nossos históricos de navegação.

Os programas de inteligência artificial podem conferir, por outro lado, um crescente poder de autonomia à própria tecnologia. Nesse caso estaríamos diante de uma clivagem: enquanto a tecnologia propriamente dita automatiza ou reproduz processos técnicos que, de maneira geral, ainda passam pelo escrutínio do homem, a inteligência artificial propõe a autonomia na decisão dos próprios processos tecnológicos. Passamos então de um campo predominantemente técnico para o ético.

\section{A lógica da sala de aula}

A experiência em sala de aula tem mostrado que as estratégias de ensino envolvem uma vasta gama de teorias, de abordagens pedagógicas e de recursos tecnológicos. O dado relevante, nesse caso, é o fato de que a sala de aula coloca em circulação não apenas as novas teorias, métodos e tecnologias, mas, sobretudo, oportuniza a circulação de teorias e abordagens consideradas ultrapassadas (retrógradas, tradicionais) e recursos tecnológicos considerados "obsoletos" (lousa e giz, por exemplo).

Ao colocar em circulação teorias, métodos e espaços diferenciais, algumas estratégias oportunizam a mobilização e/ou reconfiguração do velho e do novo em uma perspectiva não coincidente com a modernidade na acepção baudelairiana, uma vez que não se trata apenas de articular o novo com o velho, mas de colocar em circulação as molduras da própria modernidade, ou seja, a encenação da representação da representação.

No sentido aqui proposto, a sala de aula não é um conceito idealista, abstrato, mas é dotada de uma existência própria. É nela que, teoricamente, se deveria realizar o ensino sistemático. Parte da chamada crise da sala de aula relacionase com a imperiosa necessidade de se colocar em prática o que está descrito nos planos de ensino, nas ementas das disciplinas e nas políticas públicas curriculares. Como ser existente concreto, a sala de aula, no entanto, "resiste" às políticas de uniformização e, como um interlocutor em situação de diálogo, se posiciona para uma troca ou para uma negociação que pode ser conflituosa ou não. Desse modo, aspectos dos conhecimentos recebidos de maneira informal e também os adquiridos 
de maneira não formal (por exemplo um curso de desenho realizado pela internet) afloram no ambiente escolar de maneira espontânea. Nesse sentido, o diálogo da educação formal com os conhecimentos prévios é o melhor exemplo de como o aprendizado deve se realizar em sala de aula.

A situação de diálogo a que nos referimos é tributária das contribuições de Bakhtin (1988; 1999; 2000; 2010). Para ele o dialogismo está presente em todo discurso: pode ser sob a forma de uma réplica em uma simples situação de diálogo, pode aparecer como resposta a um horizonte discursivo, pode aparecer na relação entre narrador e personagens, na relação entre diferentes gêneros discursivos, entre outros. Importante destacar que na teoria de Bakhtin, apesar de haver diálogo em todas situações discursivas, existem situações em que o processo de reificação é maior ou menor. Assim, por exemplo, no romance, o discurso indireto é potencialmente mais reificador que o discurso indireto livre.

Durante muito tempo Bakhtin buscou na literatura exemplos de vozes realmente livres. Após o estudo da obra de Dostoiévski, ele concluiu que nos romances deste autor, a voz do herói alcançou um nível tão alto de independência que fez calar a voz do autor. Bakhtin chamou esse tipo de romance de polifônico, uma vez que nele todas as vozes deixam de ser reificadas pelo autor. Todavia, nas últimas obras, o estudioso russo, aparentemente, abandonou o termo polifonia e o substituiu por multilinguismo, que, em Questões de literatura e estética (1988), é interpretado como múltiplas vozes. De acordo com alguns autores, dentre os quais Tezza (2003), a polifonia só teria ocorrido na obra de Dostoiévski.

Apesar de em toda situação de discurso haver diálogo, há situações nas quais a interação nasce espontaneamente, como no caso das relações face a face. $\mathrm{O}$ professor, em situação de aula, precisa negociar os conteúdos, ou seja, estar na posição de quem ouve: ele não pode ser uma voz reificadora, normativa. Entretanto, uma grande quantidade de autores insiste em afirmar que a sala de aula é um espaço tradicional, retrógrado, em que há um sujeito em uma posição privilegiada cuja responsabilidade é transmitir os conhecimentos aos alunos.

$\mathrm{Na}$ verdade, o elemento tradicional das salas de aula - por exemplo, as mesas e cadeiras alinhadas, dispersas, ou gramaticalmente circulares, isso pouco importa - é um convite para um diálogo efetivo nos termos bakhtinianos. Assim a 
sala de aula já surge diante dos nossos olhos como uma pergunta que, na maioria das vezes, é sequer formulada. Por outras palavras, podemos dizer que a sala de aula — onde quer que esta seja instalada — é uma voz coletiva.

A sugestão de que a escola, enquanto espaço territorializado, deve se posicionar na condição de interlocutora de outros espaços difere da concepção de espaço disciplinar em Michael Foucault ou de Aparelho Ideológico de Estado formulado por Louis Althusser (1996). A diferença, neste caso, não significa divergência, mas a adoção de outra perspectiva que não a de sujeito-objeto. Assim, em lugar de se pensar a instituição escolar como um Aparelho Ideológico de Estado, no qual se realiza a luta de classes, segundo a acepção de Althusser, preferimos pensá-la, na esteira do pensamento de Pêcheux (1996), como um lugar de reprodução/transformação. O que está em questão aqui é um processo iterativo e circular em que sujeitos (ou "pessoas") estabelecem-se um em relação ao outro mediante um diálogo efetivo.

Entendemos que o espaço escolar é um lugar onde o saber é sempre rasurado e, se podemos falar em uma identidade escolar, esta então é formada por saberes rasurados. A sua voz é sempre tensa. Tal tensão é tanto mais efetiva quanto maior for a busca pela racionalidade. Quando o saber escolar, por diferentes motivos, abandona a sua tarefa de fazer circular o conhecimento sistemático, a tensão diminui e a própria escola deixa de fazer sentido.

\section{Estilos de aprendizagem}

Uma grande parte dos trabalhos realizados em língua espanhola faz referência aos EA desenvolvidos por Alonso, Gallego e Honey. De fato, os milhares de artigos publicados sobre os EA que citam os referidos autores são um atestado de sua validade e importância no contexto da aprendizagem individual. Nesse sentido, o Cuestionario Honey-Alonso de Estilos de Aprendizaje (CHAEA) assumiu um papel de grande destaque nos estudos sobre os EA em língua espanhola.

O objetivo do questionário é identificar características individuais derivadas de quatros EA, a saber, o estilo teórico, o estilo reflexivo, o estilo pragmático e o 
estilo ativo. O CHAEA é composto por 80 perguntas sendo que cada uma delas está relacionada com um desses quatro estilos. Assim, o resultado de cada aluno ou turma pode ser registrado como uma combinação de estilos, podendo resultar na dominância de um estilo ou na combinação de dois ou mais estilos.

De qualquer forma, a maioria dos trabalhos que envolvem o questionário Honey-Alonso são densos e permeados de muitas tabelas e gráficos. Há um predomínio da dimensão técnica e a sua aplicabilidade parece estar muito adaptada aos ambientes virtuais, a começar pelas perguntas, cujas respostas estão condicionadas a um "sim" ou a um "não"; em outras palavras, à linguagem binária ligado/desligado. Entendemos que essa é uma tendência em determinadas áreas e isso não constitui problema algum, desde que se compreenda que os textos falam por si. Nesse sentido a obra Estilos de aprendizagem e o uso das tecnologias, de Barros (2013) representa um esforço gigantesco para a compreensão dos EA no espaço virtual. Apesar da defesa apaixonada pela tecnologia digital, a autora não fez uso de tabelas complexas, ou seja, não dramatizou a narrativa da técnica.

No entanto, o modelo de Alonso pode seguir outros caminhos que não o do meramente técnico. Nesse sentido, na obra Estilos y estrategias de aprendizaje: aplicación práctica en el aula, Camerina Cobos Varilla (2019) demonstrou que os EA do referido autor podem ser aplicados em diferentes situações de ensino, inclusive na sala de aula.

Assim, sem prejuízo para os inúmeros trabalhos envolvendo os EA no espaço tecnológico, consideramos que a defesa intransigente da sala de aula assume uma importância crucial justamente no momento em que esse espaço passa por um rápido processo de substituição.

\section{Estratégias de estilos de aprendizagem em sala de aula}

Em Estilos y estrategias de aprendizaje: aplicación práctica en el aula, Varilla (2019) propôs uma grande quantidade de estratégias, tendo como referência os estilos de aprendizagem propostos por Alonso, Gallego e Honey (2007).

O trabalho apresenta os diferentes aspectos envolvendo os EA. Digno de nota, é a maneira pela qual a autora subdivide as estratégias, na busca de cobrir um 
amplo espectro de situações práticas (e também teóricas), bem como o potencial de cada um dos estilos. Assim, por exemplo, no capítulo denominado "Estrategias de aprendizaje para estilos teóricos", a autora subdivide o tema em cinco partes: analogias, quadros sinóticos, ensaios, pistas tipográficas, resumo. Com relação a ensaios, Cobos Varilla afirma haver dois tipos: no primeiro, de caráter pessoal, o autor fala de si mesmo e de suas opiniões sobre fatos e coisas, com um estilo ligeiro e natural, quase convencional; no segundo, de caráter formal, o discurso é mais ambicioso, extenso e de controle formal e rigoroso. Ele se aproxima do trabalho científico, no entanto, sempre contém o ponto de vista do autor (COBOS VARILLA, 2019).

Quadro 1 - Exemplos de estratégias

\begin{tabular}{|l|l|l|l|}
\hline Teórico & Reflexivo & Pragmático & Ativo \\
\hline Analogias & Organizadores gráficos & Atividades de & Wikis \\
Quadros sinóticos & Mapa mental & repetição e prática & Plataformas educativas \\
Pistas tipográficas & Diagrama & Enquadramento & Ilustrações \\
Resumo & Redes sistemáticas & Método de casos & Brainstorming \\
& Mapas conceituais & Estratégias para & RPG \\
& Mapas cognitivos & orientar a atenção dos & Portfólios \\
& Perguntas & alunos & Debate \\
& & Objetivos ou intenções & Ler em voz alta \\
& & Situação problema & Busca de informações \\
& & & Revisão \\
& & & Palavras cruzadas \\
& & & Revisão de aprendizagem \\
\hline
\end{tabular}

Fonte: Adaptado de Cobos Varilla (2019).

Albin Hobon (2019), no prólogo deste mesmo livro, salienta que a princípio o texto parece ser uma obra apenas de metodologia de aprendizagem e de estratégias, no entanto, ele alerta que o livro vai mais além dos que os convencionais. Um desses aspectos que ultrapassam a mera metodologia é o fato de a autora se valer de uma das estratégias de estilos de aprendizagem para compor o próprio livro, a saber, o uso de pistas de aprendizagem, que vai conferir à obra não apenas uma facilidade na compreensão, mas também contribui para uma argumentação sólida didático-pedagógica sustentada em uma ampla e direta bibliografia atualizada. Embora Hobon faça um elogio a Augusto Comte, afinando-se com a ideia de que uma das finalidades da educação é disciplinar a inteligência, a obra de Cobos Varilla não parece compactuar 
inteiramente com essa afirmação: sem abrir mão do rigor, as estratégias propostas para os EA também se apresentam como um guia para uma infinidade de outras estratégias.

As estratégias apresentadas por Cobos Varilla são uma amostra de como se pode trabalhar os EA formulados por Alonso em sala de aula. Apesar de a autora ter-se focado apenas nos estilos puros, é possível supor que essas estratégias possam ser desdobradas focando estilos híbridos, como teórico/reflexivo ou teórico/pragmático, por exemplo. Desse modo, fica implícito em seu trabalho a preocupação com a expansão das capacidades evitando que o aluno desenvolva apenas um estilo.

Outro texto digno de nota é o capítulo "Estilos de Aprendizaje en aula" escrito por Rodríguez et al. (2015) que é parte da coletânea intitulada Estilos de aprendizaje: desafios para una educación inclusiva e innovadora, organizada por Gallego, Alonso e Barros. No referido capítulo, os autores elaboram um quadro com diversas estratégias para ser usadas em sala de aula. Embora muito semelhante ao trabalho de Cobos Varilla, as propostas dos referidos autores contemplam os estilos híbridos, fornecendo um amplo espectro de estilos personalizados.

\section{Estratégias de EA com o uso da narrativa truncada}

A sala de aula, injustificadamente designada como retrógrada, representa uma das formas mais eficazes de combate à reificação promovida por uma visão distorcida da tecnologia. A sociedade de controle não pode ser concebida como um fatalismo. Interpretar as tecnologias digitais, a internet e as redes sociais como um desafio de alta complexidade ainda é melhor que aceitar passivamente que a escola deva seguir, pari passu, a contínua aceleração e liquefação das relações sociais. Como já se afirmou anteriormente o que está em questão é a autonomia do homem como o concebemos, então estamos diante de um dilema ético.

Pelo exposto, no que diz respeito aos EA, a experiência de longos anos mostra que eles podem perfeitamente ser utilizados como estratégias na sala de aula, 
uma vez que, de qualquer modo, o professor terá que negociar cada um dos estilos. Exemplos desse ponto de vista se encontram na obra de Cobos Varilla (2019) e de Rodríguez et al. (2015), que, mediante uma exposição simples de estratégias, apontam caminhos produtivos.

O que é significativo na proposta da autora é que cada uma das estratégias escolhidas é explicada didaticamente, tendo em vista, como salienta Rodríguez et al. (2015), que o conceito de estratégias didáticas inclui tanto as estratégias de aprendizagem (perspectiva do aluno) quando as estratégias de ensino (perspectiva do professor). Como a autora explicou, elas constituem um guia para o professor e também para o aluno; desse modo podem ser ampliadas de acordo com a atividade proposta.

Assim, na escolha de uma estratégia, o professor deve selecionar aquela que melhor se adequa ao trabalho a ser desenvolvido. Essa estratégia assumirá o ponto de vista do professor. Como supõe-se que as atividades são programadas, o dizer do professor, neste caso específico, é sempre sistemático e também normativo, uma vez que o discurso dele reproduz o discurso da escola no que diz respeito à sua faceta institucional. Não vemos problema algum nisso, mas grande parte da incompreensão dos trabalhos em sala de aula resulta de uma interpretação inadequada do papel do professor, que está ali, para, lembremos, criar as condições para que o saber sistemático circule em sala de aula.

\section{Exemplo de uma estratégia com narrativa truncada}

Objetivo principal: diagnóstico das principais tendências de estilo de aprendizagem Objetivo secundário: interação e autoaprendizagem

Duração: 2 aulas

Materiais: lousa, giz, caderno, lápis, caneta, smartphone, Datashow

Estratégia escolhida: brainstorming (ponto de vista do professor).

O brainstorming é uma estratégia de grupo usada para gerar ideias originais em um ambiente descontraído, o que significa que membros de um grupo podem falar de um determinado tema ou sobre uma questão com liberdade e sem inibições. O objetivo é produzir ideias originais, gerar novas soluções e estabelecer novas 
relações entre os fatos e integrá-los [diríamos aqui relacioná-los] de maneira diferente (COBOS VARILLA, 2019, p. 8-9).

Para a atividade foram utilizados os quatro tipos de estilos propostos por Alonso, Gallego e Honey (2002): teórico, reflexivo, pragmático e ativo. O estilo teórico está representado em negrito, o estilo reflexivo em itálico, o estilo pragmático com sublinhado e o estilo ativo com negrito e sublinhado.

Considerou-se para essa atividade três tipos de conhecimento: o conhecimento sistemático, representado pela voz do professor e identificado por dois colchetes. O conhecimento informal, representado pela resposta dos alunos e identificado com dois parênteses. O conhecimento relativamente sistemático, representado também pelas respostas dos alunos e identificado com duas chaves.

O uso da narrativa truncada, ou sequência de ações sem a mediação de um narrador explícito, tem por objetivo diminuir a autoridade do autor. Desse modo, não há necessidade de questionário. O professor, na medida em que observa, vai descrevendo cada ação. A duração da atividade deve ser negociada com os alunos. O desenho final é representado por uma narração-truncada realizada in loco pelo professor; justamente por isso a atividade não é totalmente controlada.

[DECLAMAÇÃO DO POEMA "AMOR É FOGO QUE DÓI E NÃO SE SENTE"] (LEVANTAR A MÃO) (DECLAMAÇÃO DO POEMA) [DECORAR O POEMA] (PERGUNTA) (LEVANTAR A MÃO) [PESQUISA SOBRE O AUTOR NO SMARTPHONE] (PERGUNTA) \{PESQUISA\} [ELABORAÇÃO DE MAPA CONCEITUAL SOBRE BIOGRAFIA DO AUTOR NO CADERNO] \{MAPA CONCEITUAL\} [EXPOSIÇÃO DOS MAPAS CONCEITUAIS NO DATASHOW]\{EXPOSIÇÃO DA PESQUISA\} [ANÁLISE ESTILÍSTICA DO POEMA] [PERGUNTAS] (RESPOSTAS) \{RESPOSTAS\} [ESCREVER SOBRE O TEMA] (TEXTO) \{TEXTO\}. [ASSISTIR FILME SOBRE CAMÕES] (ASSISTIR FILME) [SINOPSE DO FILME] (SINOPSE) \{SINOPSE\} [COMPARAR FILME E POEMA] \{PERGUNTA\} (ANALOGIA) \{ANALOGIA\} [ELABORAÇÃO DE UM VÍDEO] (VÍDEO) \{VÍDEO (DECLAMAÇ̃̃OO DO POEMA DECORADO).

Esse é mais ou menos o resultado do desenho narrativo da estratégia, que representa a voz do professor, a qual, em tal circunstância, já não é mais uma voz sistemática e normativa. Nesse caso, já se trata de um conhecimento de natureza relativamente sistemática, ou seja, conhecimento em construção, portanto sujeito a erros nas marcações. No final do exercício, o professor projeta no Datashow o esquema da narrativa truncada que ele elaborou durante a aula. Nesse momento o professor e os alunos discutem os EA utilizados e, muito importante, juntos corrigem o sistema de 
marcação que com muita probabilidade terá erros (a própria voz do professor é rasurada). Resumindo, as vozes sintaticamente horizontalizadas e aliadas a um movimento iterativo e circular buscam encenar a mesma posição do autor em Dostoiérski. Desse modo cria-se um ambiente cultural propício à circulação de vozes em posição de igualdade.

O resultado final, como se pode deduzir, é a representação dinâmica do processo de ensino e aprendizagem em que as chances de erros e acertos se distribuem de maneira equilibrada entre o professor e os alunos. Espera-se que o diálogo entre os conhecimentos sistemáticos e informais produza um tipo de conhecimento relativamente sistemático em suas múltiplas tonalidades.

Outra observação pertinente refere-se ao uso das tecnologias. Elas devem ser simples, leves e fáceis de serem manipuladas em sala de aula. Nesse caso, a voz da tecnologia dialoga de igual para igual com as demais vozes: ela se torna eficiente na medida humana, pois são instáveis e imprevisíveis: um celular pode não funcionar, o Datashow pode apresentar problemas com o cabo, o vídeo poder ficar muito escuro ou embaçado, a wi-fi pode cair. Todos esses acontecimentos se traduzem sob a forma de diálogos efetivos, por isso mesmo a tecnologia em tais circunstâncias leva para a sala de aula um conhecimento significativo sobre ela mesma em sua relação com o cotidiano.

\section{Considerações finais}

Nesse artigo sugeriu-se que os EA sejam utilizados como instrumentos facilitadores da aprendizagem em um ambiente verdadeiramente dialógico, como a sala de aula.

Nesse sentido, poder-se-ia dizer que a tecnologia da sala de aula se consubstancia na sua vocação natural em distribuir de maneira dialógica as diferentes formas de aprender. Esse potencial da sala de aula só se tornou claro com o advento do ensino nos espaços virtuais. A agência da máquina nos ambientes tecnológicos circula em meio a uma desconfiança: não seriam os mecanismos tecnológicos (questionários, gráficos, algoritmos) os responsáveis pela determinação dos estilos individuais de cada aluno? 
Do mesmo modo, procurou-se demonstrar que a voz da tecnologia digital no contexto da sala de aula, quando circula dialogicamente, não exerce nenhum poder normativo, ao contrário do que ocorre, por exemplo nas redes sociais com o Youtube e também em alguns cursos em EAD.

Por outro lado, os EA nos ambientes virtuais não nos fornecem qualquer garantia para o enfrentamento de um mundo cada vez mais veloz e imprevisível. Pelo contrário, a experiência mostra que os recursos tecnológicos de ponta são mais suscetíveis de obsolescência que os mais simples e tradicionais. Se o que esperamos é uma maior penetrabilidade da cultura tecnológica na sala de aula, aquela, segundo nos parece, não se fará pela via da agência tecnológica, mas sim pelo envolvimento pessoal da aprendizagem. Desse modo, sugere-se que é a cultura humana que deve transpirar pelos poros da máquina e não o contrário.

\section{Referências}

ALONSO, C. M.; GALLEGO, D. Aprendizaje y ordenador. Madrid: Dykinson, 2000.

ALONSO, C. M.; GALLEGO, D. J.; HONEY, P. Los estilos de aprendizaje: procedimientos de diagnóstico y mejora. Bilbao: Mensajero., 2007.

ALONSO, C. M.; GALlEGO, J. D; HONEY, P. Cuestionario Honey-Alonso de Estilos de Aprendizaje (CHAEA). In: BARROS, V. M. D. Teoria dos estilos de aprendizagem: convergência com as tecnologias digitais. Revista SER: Saber, Educação e Reflexão. Agudos, v.1, jul./dez., 2008. Disponível em: <https://repositorioaberto.uab.pt/bitstream/10400.2 /2999/3/70-228-1-PB\%202.pdf>. Acesso em: 10 de out. 2019.

ALTHUSSER, L. Ideologia e aparelhos ideológicos de estado (notas para uma investigação). In: ZIZEK, S. Um mapa da ideologia. Rio de Janeiro: Contraponto, 1996.

BAKHTIN, M. Problemas da poética de Dostoiévski. Trad. Paulo Bezerra. 5. ed. rev. Rio de Janeiro: Forense Universitária, 2010.

BAKHTIN, M. Estética da criação verbal. Trad. Maria Ermantina Galvão; rev. trad. Marina Appenzeller. 3. ed. São Paulo: Martins Fontes, 2000.

BAKHTIN, M. (VOLOSHINOV). Marxismo e filosofia da linguagem: problemas fundamentais do método sociológico na ciência da linguagem. Trad. Michel Lahud e Yara Frateschi Vieira. 9. ed. São Paulo: Hucitec, 1999.

BAKHTIN, M. Questões de literatura e de estética: a teoria do romance. Trad. Aurora F. Bernardini. São Paulo: Hucitec, 1988.

BARROS, D. M. V. Estilos de aprendizagem e o uso das tecnologias. Santo Tirso: De Facto Editores, 2013. 
BARROS, D. M. V. et al. (Org.). Estilos de Aprendizagem e inovação pedagógica. Santo Tirso: Whitebooks, 2016.

COBOS VARILLA, C. Estilos y estrategias de aprendizaje: Aplicación práctica en el aula (Spanish Edition) [S.1.]: ISICE, 2019.

ENGUITA, M. F. Redes para la innovación educativa. Cuadernos de pedagogia, n. 374, 2007. Disponível em: < https://www.researchgate.net/publication/39221777_Redes_para_la_innovacion_educativa $>$. Acesso em: 10 nov. 2019.

FELDER, R. M.; SILVERMAN, L. K. Learning and teaching styles in engineering education. Engineering Education, v. 78, n. 7, p. 674-681, 1988.

GALlEGO, D. J. ; ALONSO, C. M. Prólogo. In: MIRANDA, L.; ALVES, P.; MORAIS, C.; BARROS, D. (Org.). Estilos de Aprendizagem e inovação pedagógica. 2016. Edição do Kindle.

GALLEGO RODRÍGUEZ, A.; MARTINEZ CARO, E. Estilos de aprendizaje y e-learning. hacia un mayor rendimiento académico. Revista de Educación a Distancia, v. 3, n. 7, p. 1-10, 2003.

HOBON, A. Prólogo In: COBOS VARILLA, C. Estilos y estrategias de aprendizaje: Aplicación práctica en el aula. [S.1.]: ISICE, 2019. p. 6.

KUSSLER, L. M. Técnica, tecnologia e tecnociência: da filosofia antiga à filosofia contemporânea. Kinesis, v. 7 n. 15, 2015. Disponível em: $<$ http://www2.marilia.unesp.br/revistas/index.php/kinesis/article/view/5712>. Acesso em: 10 out. 2019.

LÓPEZ RUPÉREZ, F.; GARCÍA GARCÍA, I.; EXPÓSITO CASAS, E. La calidad de la gobernanza del sistema educativo español: un estudio empírico. Madrid: Universidad Camilo José Cela, 2017. Disponível em: <https://repositorio.ucjc.edu/handle/20.500.12020/825>. Acesso em: 10 out. 2019.

MARINA, J. A. La profesión docente. Madrid: Fundación Santillana, 2016. Disponível em: $<$ http://www.fundacionsantillana.com/PDFs/folleto_j_a_marina.pdf > . Acesso em: 10 out. 2019.

OLDS, P. R.; SPINDLE, R. M.; CEREOLA, S. J. The interaction of teaching and learning styles in the second introductory accounting course. American Accounting Association Annual Meeting, Chicago, 2007.

PERAL, I. M. La enseñanza de la lecto-escritura a través de la prensa escrita. El Español en Contexto: Actas de las XV Jornadas sobre la lengua española y su enseñanza, 2010.

PECHÊUX, M. O mecanismo do (des)conhecimento ideológico. In: ZIZEK, S. Um mapa da ideologia. Rio de Janeiro: Contraponto, 1996.

RODRÍGUEZ, A. L. et al. Estilos de Aprendizaje en aula. In: GALLEGO, D. J.; ALONSO, C. M.; BARROS, D. M. (Org.). Estilos de Aprendizaje: Desafíos para una educación inclusiva e innovadora. Santo Tirso: Whitebooks, 2015. (Estudos Pedagógicos Dinâmicas Educacionais Contemporâneas, n. 6). Edição do Kindle.

SANTAELLA, L. Como eu ensino leitura de imagens. São Paulo: Melhoramentos, 2012. 
TERRELL, S. R.; DRINGUS, L. An Investigation of the effect of learning style on student success in an online learning environment. Journal Educational Technology Systems, v. 28, n. 1, p. 231-238, 2000.

TEZZA, C. Entre a prosa e a poesia: Bakhtin e o formalismo russo. Rio de Janeiro: Rocco, 2003.

VIDAL, J. P. Proyecto "Libro Abierto". Pulso Revista de Educación, n. 31, p. 181-196, 2008. Disponível em: <https://revistas.cardenalcisneros.es/index.php/PULSO/article/view/81>. Acesso em: 10 out. 2019.

RECEBIDO: $30 / 11 / 2019$

APROVADO: 05/02/2020

RECEIVED: $11 / 30 / 2019$

APPROVED: 02/05/2020

RECIBIDO: $30 / 11 / 2019$

APROBADO: 05/02/2020 